\title{
A potência oralizante da multidão: por que os estudos culturais ajudam a compreender a experiência dos muitos na literatura contemporânea
}

Luciano Barbosa Justino $^{1}$

A estreita ligação entre os estudos literários e os estudos culturais já possui hoje uma tradição teórico-crítica. Os estudos culturais continuam sendo um importante impulsionador do pensamento sobre a literatura no presente, ainda mais quando articulados com outra tradição não menos importante, o pós-estruturalismo.

A articulação entre uma teoria crítica da linguagem cujo horizonte é a alteridade com uma não menos crítica visão da cultura a partir da experiência da recepção de grupos minoritários foi o melhor que poderia acontecer ao "engajamento elitista" e "constituinte" que sempre marcou os estudos literários no decorrer do "longo" século XX.

Lembre-se, contudo, que dada a natureza antropofágica e barroca da América Latina como resistência à linearidade do cânone colonial e a seus projetos de estandardização à europeia, a experiência do encontro com a diferença minoritária, em suas muitas tensões e potenciais revolucionários, e o esmaecimento de fronteiras disciplinares nos acompanham desde sempre, demonstram os sermões do Padre no longínquo século XVII e o não menos distante sertões de Euclides, antropológico, histórico, sociológico, ecocrítico, literário.

Entre nós, a contribuição dos estudos culturais e do pósestruturalismo tornou mais densa a problematização de nossas maneiras dominantes de abordar os objetos da cultura. Como afirmou certa vez Ana Pizarro, a experiência colonial exige que dessubstancializemos as fronteiras disciplinares e assumamos "ampla abordagem cultural, num espaço de fusão, de interseção de disciplinas" (Pizarro, 1993, p. 21).

No que diz respeito a metodologias de abordagem do texto literário, das estratégias de leitura que empreendemos para dar conta da multiplicidade que os textos de literatura contemporânea encenam, penso que continuamos, contudo, ainda presos aos modelos de leitura e

\footnotetext{
${ }^{1}$ Doutor em letras e professor da Universidade Estadual da Paraíba (UEPB), Campina Grande, PB, Brasil. E-mail: lucianobjustino@cnpq.pq.br
} 
por extensão de prática crítica herdados da modernidade. Somos ainda excessivamente textualistas e identitários.

Se as importantes contribuições dos estudos culturais e do pósestruturalismo nos estudos literários nos deram um aparato teóricocrítico vasto para questionarmos a subalternização das minorias e de seus produtos culturais, ainda estamos carentes de métodos de leitura literária que nos permitam ir além dos modelos constituintes de leitura próprios da autonomia do campo literário e de seu correspondente conceito de escrita - de escrita dita literária.

Os produtos culturais das minorias, em sua potência de multiplicidade, são diluídos na tradição literária moderna de tal modo que só podem ser pensados dentro daquilo que reitera essa mesma tradição, de um ponto de vista teórico-metodológico, traduzindo-a. Não que os estudos literários tenham fechado os olhos para as "potências dos pobres"; longe disso, os meios e modos de alcançá-los é que mudou muito pouco. Nossos métodos não mudaram muito em relação ao quadro a partir do qual afirmava, no início dos anos 1990, Ria Lamaire, "a genealogia e a história literária criam a ilusão de uma só história, de uma única tradição. Este mito é reforçado continuamente em cada descrição genealógica e em cada versão da história literária" (Lamaire, 1994, p. 59).

Todo novo construto teórico e toda nova visibilização da diferença, assim como sua crítica, só podem surtir o seu verdadeiro efeito na abordagem do texto literário se aparecerem acompanhados de novos métodos de entrada nas obras. Do contrário, seus potenciais teóricocríticos são tolhidos pela mesmeridade de uma memória de exclusão que os ideologiza desde dentro.

Ainda não desenvolvemos bons métodos capazes de dar conta da articulação da literatura com a experiência do cotidiano que as obras demarcam e que penso ser o grande legado dos estudos culturais, pelo menos em seu projeto inicial. O incômodo da crítica é o substrato de "mercadoria", reificada, estetizada e substancialista de seus métodos.

Acredito que o conceito de multidão como "um conjunto de singularidades cooperantes" pode nos livrar do ranço literário da leitura que chamo de identitária, baseada em princípios disciplinares de identidade e que impregnam ainda as abordagens étnicas, de gênero e geração abertas pelos estudos culturais.

Os muitos dessa mesma multidão, que é sempre outra, oralizam, semiose-contra-hegemônica dos muitos, a literatura. Edouard Glissant 
pensou numa oralização da literatura como alternativa à estandardização da produção cultural sob o capitalismo global. Os estudos de Jean Derive sobre a escrita nas literaturas africanas ajudam a compreender a produtividade da experiência cotidiana de ler e escrever num mundo onde não se pode pensar os fenômenos senão levando em conta os modos de vida que articulam solidariedades e lutas por demandas tantas, inclusive do direito à escrita, que atravessam o fazer literatura no contemporâneo.

\section{A literatura diante das formas de vida contemporâneas}

É sintomático que um dos livros fundadores dos estudos culturais, Cultura e sociedade: de Coleridge a Orwell, de Raymond Williams, tenha na literatura suas principais fontes. As fontes de Williams são escritores e poetas ou pensadores que estão próximos da literatura. A literatura é um espaço privilegiado da virada culturalista. Por quê?

Três hipóteses parecem-me centrais: a primeira delas, implícita no livro, é que o percurso empreendido por Williams está associado aos processos de expansão dos usos da escrita na sociedade inglesa e ao cada vez mais influente papel da literatura como gênero do discurso na formação intelectual inglesa até o alto modernismo. A segunda é o que quero chamar de função ambivalente da literatura, que tanto semiotiza as transformações sociais em curso rumo a uma visão materialista da cultura pensada no cotidiano quanto fundamenta um processo de hierarquização e autonomia do cultural em sua relação com a cultura popular e de massa.

Tal hierarquização está na base do conceito modernista de literatura com seus muitos desdobramentos, inclusive da hegemonia do texto e de uma leitura textualista da obra literária, ensinados inclusive nas escolas. Uma ciência da literatura só pode surgir a partir de tais transformações e de suas ambivalências.

A terceira, e que considero a mais importante como vetor para investimentos futuros, é a capacidade intrínseca, constitutiva, da literatura na semiotização da alteridade, na encenação das vivências do homem comum produzindo cultura a toda hora. Na ausência de uma "ciência do cotidiano", continua sendo a literatura a semiotizá-lo, suas muitas relações intersubjetivas, com as estruturas do poder e as 
instituições sociais, as memórias, os projetos coletivos e pessoais, as tensões nos momentos de rupturas, as utopias societárias.

O livro de Williams, na medida em que articula tais transformações com o modo dos escritores modernos lidar com elas, com especial atenção para os estreitamentos próprios da primeira metade do século $X X$, contém três premissas que precisam ser exploradas em toda a sua riqueza, sobretudo naquilo que facultam, até exigem, novas metodologias de abordagem da obra literária:

a) a cultura não pode ser compreendida como uma esfera autônoma, ela está associada à experiência cotidiana da vida em comum, o que é tanto mais relevante se pensarmos na literatura como o espaço por excelência dos chamados "lugares especiais";

b) o cultural negocia com os estágios das relações sociais, de modo que uma experiência "estratificada" se transforma em produto, em "texto", em obra, em literatura; e

c) a cultura implica relações assimétricas de poder e estruturas sociais de onde os produtos culturais nascem, revalidam, resistem (Cf. Williams, 2011; Johnson, 2000, p. 13).

Isso posto, penso que os estudos culturais ainda podem oferecer mais aos estudos literários, há aspectos do projeto de Williams ainda pouco explorados: pensar a cultura como prática participativa em comum, como solidariedade constitutiva, com todas as consequências interdisciplinares, interculturais e intersemióticas que isso implica.

Se em suas origens os estudos culturais foram buscar nos estudos literários seus principais modos de abordar a produtividade da cultura a partir de baixo, ainda não fizemos o processo inverso em toda sua potencialidade. Não estou com isso querendo dizer que os estudos literários, desde o longínquo ano de 1958, quando Williams publicou seu livro, não se modificaram nem se enriqueceram. Não se trata disso; antes, ao contrário, os estudos literários perderam muito de seu ranço elitista e reacionário, de seu engajamento conservador, o que devemos saldar com todos os vivas.

O que quero dizer é outra coisa: nossos métodos, nossas entradas nas obras, nossos modos de ler e escrever, continuam devedores de uma velha tradição individualista, identitária e estetizante. Abrimo-nos para 
visadas sociológicas, antropológicas, tecnológicas, comunicativas etc., mas continuamos usando a mesma viseira, os mesmos velhos princípios dominantes que consideramos os mais relevantes nas obras, personagens, narradores, eu-textual, estilo de época, contexto histórico, todos no mais das vezes partindo de uma implícita autonomia do literário que compreende o texto como origem e não resultado do modo de entrada nas obras.

Ainda estamos procurando os velhos princípios identitários que a modernidade nos legou, não obstante a expansão do escopo de interesse e de uma positiva politização do debate. Nosso modo de entrar nas obras ainda continua excessivamente "modernista". No lugar de fazermos falar os silêncios das obras canônicas, preferimos a tagarelice das obras minoritárias, mas ainda com os mesmos métodos que empregávamos para lermos os "clássicos". Ou seja, falta a multidão em sua multiplicidade constitutiva, não como "personagem", mas principalmente como método crítico, em outras palavras, falta a multidão como ética da leitura.

Ainda não passamos, em literatura, do indivíduo à solidariedade, temos dito muito pouco sobre a cultura em comum ou o comum da cultura, continuamos compreendendo fragmentariamente o cultural e fechando os "olhos, boca, narinas e orelhas" para o problema central dos estudos culturais: pensar "como as formas de vida de uma sociedade moldam seus projetos e obras" (Cevasco, 2003, p. 65).

De certo modo, a virada antropológica e política inerente aos estudos culturais ainda não nos alcançou naquilo que tem de crítica da objetualização da experiência que o nosso apego às obras e aos textos só repropõem a toda vez, como a domar os muitos movimentos de significação dos quais os produtos culturais são o resultado.

As qualidades humanas e a dimensão sensorial da experiência são objetificadas e abstraídas ou "separadas" das pessoas e suas atividades, de maneira a tornarem-se produtos em si, "reificadas ou estetizadas". O problema é, então, como reverter ou romper esse processo, de modo a reaver ou a reafirmar todas as qualidades humanas que a mercadoria nega por abstração (Willis, 1997, p. 19).

Nos nossos contextos pós-modernos, que implicam um novo estatuto da produção e do consumo, de outra dinâmica das formas e dos saberes, de uma nova economia simbólica com seus capitais culturais ao mesmo tempo globais e locais, desterritorializados e 
fortemente "regionais", a literatura contemporânea, em particular no Brasil e na América Latina, não tem deixado de explorar esses movimentos difusos e fortemente incrustados na experiência comum do homem comum. Mas as leituras teórico-críticas têm facultado pouco os resultados que podemos tirar disso. $\mathrm{O}$ encontro com essa experiência comum, ou do comum, para as quais os estudos culturais muito nos deram estou chamando de literatura de multidão.

Uma maneira de nos livrarmos do ranço modernista no pensamento sobre a literatura e atualizarmos o potencial teórico-crítico dos estudos culturais é observarmos o potencial crítico do conceito de multidão, que ressignifica os objetos a partir da experiência e de sua partilha, pressupondo a recusa do "papaguear identitário" da massa e do povo como consciência dos riscos essencializantes das identidades e das individualidades de substância e transcendência.

Não estamos aqui diante de individualidade e sim diante de singularidades. Individualidade significa algo que está inserido em uma realidade substancial, algo que tem uma alma, uma consistência, por separação em relação à totalidade, em relação ao conjunto. É algo que tem uma potência centrípeta. O conceito de indivíduo é de fato um conceito que é colocado a partir da transcendência em que relação não é algo entre eu, tu e ele, mas uma relação do indivíduo com uma realidade transcendente, absoluta, o que dá a essa persona a consistência de uma identidade irredutível. A multidão não é assim, vivemos com os outros, a multidão é o reconhecimento do outro. A singularidade é o homem que vive na relação com o outro, que se define na relação com o outro. Sem o outro ele não existe em si mesmo (Negri, 2010, p. 3).

O povo e a massa são identitários. A despeito do que possa parecer à primeira vista, tanto povo quanto massa pressupõem unidades centrípetas e estão na mesma chave "ontológica" com a qual pensamos a cultura erudita em geral e a literatura em particular. $\mathrm{O}$ povo, etnolinguístico e etnocêntrico, fundamenta a unidade do Estado-nação; a massa, acinzentada e diluída num essencial não ser, fundamenta o consumo a partir da ideia de um consumidor tão alienado quanto passivo.

Pensar o fim da massa e do povo a partir da "potência ontológica da multidão" não é negar a existência de produtos culturais que por razões ideológicas foram definidos como tais, popular ou massivo, é abri-los a uma outra estratégia de leitura (Cf. Denning, 2005, p. 126). 
Precisamos horizontalizar a literatura para que a capacidade da cultura de produzir práticas discursivas de resistência e aferir relações materiais de poder possam nos livrar dos essencialismos que, à guisa de viés contra-hegemônico, só repropõem o estigma em outra base. Horizontalizar para irmos dos lugares especiais às vias comuns da cultura e compreendermos como as instâncias do poder aí se exercem e/ou são contestadas, com especial atenção para os modos como os produtos culturais das minorias sociais constroem estratégias de resistência aos diversos modos de dominação cultural, econômica, social.

Horizontalizar a literatura é inseri-la num "confronto total com os fatos culturais" (Mattelart e Neveu, 2004, p. 91). Nas palavras de Henry A. Giroux:

A cultura, na perspectiva mais ampla, está sempre envolvida com o poder e torna-se política em um duplo sentido. Em primeiro lugar, questões de propriedade, acesso e controle são cruciais para o entendimento do modo como o poder é empregado para regular imagens, significados e ideias que organizam as agendas que moldam a vida cotidiana. Em segundo, a cultura emprega o poder em suas conexões com o campo da subjetividade, ou seja, ela oferece identificações e noções de sujeito por meio de formas de conhecimento, valores, ideologias e práticas sociais que disponibiliza, em relações desiguais de poder, para diferentes setores das comunidades global e nacional. Como força pedagógica, a cultura reivindica certas histórias, memórias e narrativas. Segundo James Young, ela conta 'a história dos eventos e seu desdobramento como uma narrativa' para influenciar a maneira como os indivíduos adotam, modificam, resistem e acomodam-se a certas formas de cidadania cultural, às atuais relações materiais de poder e a determinadas noções de futuro (Giroux, 2003, p. 19).

Ao pesquisador da literatura se exige um novo estatuto das fontes, tanto no sentido de abrir-se para o que comumente não se inclui nos estudos literários, todas as formas de paraliteratura, quanto para olhar com outros olhares para a velha tradição literária e seus produtos. O prisma no cotidiano e no comum, na partilha do/no comum para além do texto, sem, no entanto, minimizar sua importância, retira da obra sua transcendência de origem e passa a compreendê-la como mediação, envolvendo a produção cultural em sua totalidade para dar conta da dinâmica interna da história literária e de suas formas, das 
obras particulares e de seus leitores, dos aparelhos institucionais da literatura: livrarias, "prensas", livreiros, escolas.

Se em hipótese alguma devemos jogar na lata do lixo da história os mais de cem anos de poética literária, de leitura imanente das obras, em que pese ainda os muitos riscos dos conteudismos de toda espécie, o confronto total perante a cultura há de nos prover de um olhar mais pertinente, mais em sintonia com os muitos devires da literatura contemporânea, mais capaz de dar conta da impossibilidade de domá-la numa chave única e unificante, cuja autonomia tornou-se muitas vezes a apologia da cegueira e da invisibilização.

Horizontalizar a literatura é compreendê-la materialmente a partir de outra imanência, uma imanência da totalidade de um "caos-mundo". Escrever e ler são materialidades de princípio, pois a língua, "sistema modelizante primário", é por onde passam lealdades profundas e motins de emancipação. E a literatura é seu uso mais pregnante, porque, por ela, as vozes oralizantes da multidão semiotizam seu atravessar no presente.

A outra imanência da literatura, suas máquinas, como diriam Gilles Deleuze e Félix Guattari, é dêitica porque a potência oralizante da multidão é posicional num contexto de multiplicidade, de diferença e memória pessoal e coletiva. Ela não é um modo de oposição ao popular, ao massivo e ao erudito. Ela os constitui num cronotopo de muitos em inter-relação recíproca.

\section{Pós-autonomia na multiplicidade}

Se na América Latina em geral e no Brasil em particular estamos diante de um novo ciclo de produção e circulação de bens culturais, a literatura, os "bens literários", insere-se num estágio "novo" da distribuição e dos modos de validação da cultura que modifica a utilização dos textos, inclusive os ditos literários. Pode-se pensar em dois postulados sobre literatura e cultura no mundo de hoje:

1) Todo bem cultural e literário é econômico, ou seja, está inserido na materialidade das relações de troca e transporte, fazendo muitos ecos. A cultura assume seu estatuto de "coisa num mercado", ou atravessando vários deles.

2) Todo bem cultural e literário encontra um cotidiano saturado de máquinas de produção de linguagem, cujo 
enriquecimento do mundo da cultura e dos signos embota, com tantos dizeres, toda suposta substância identitária e disciplinar, toda transparência do real, de imago e de som, de escrita e outras semioses significantes. As metáforas da velha babel estão na ordem do dia e, espera-se, não nos abandonem mais.

Não devemos fazer mais uma leitura literária da literatura. Muitos textos ditos literários sequer admitem uma "literaturização", aquele acordo tácito entre literariedade e supremacia dos problemas de linguagem, sobretudo da tensão entre ficção e realidade.

São narrativas e formas poéticas que perfazem outros movimentos de produção de sentido, aos quais Josefina Ludmer chama de "práticas literárias territoriais do cotidiano" (Ludmer, 2007, p. 11), em que a linkagem estreita vida/obra, sem crise e culpa, toma a dianteira e não mais a função autor-obra no chamado campo literário, embora a "velha" e modernista relação não deixe de ser pertinente por completo.

A uma parte dessa configuração, nova, entre escrita e cultura, Josefina Ludmer (2007) sugere a expressão "Literaturas pósautônomas". São pós-autônomas porque atravessam a fronteira da literatura e da ficção. Porque tornam indecidível o limite entre textualidade e realidade, que definia a literatura moderna, "fabricam o presente com a realidade cotidiana e essa é uma das suas políticas" (Ludmer, 2007, p. 7).

O autoinstituir-se da literatura parte do pressuposto da autonomia do espaço literário, regido por leis que têm suas próprias lógicas de produção, circulação e consumo. Importa na autonomia de campo compreender sua violência intrínseca. $\mathrm{O}$ "universo encantado da criação pura", como ironicamente o definiu Pascale Casanova em A república mundial das letras (2002), escamoteia os desafios da política literária, a existência de "guerras invisíveis" pelas "riquezas imateriais" do "capital-Cultura".

Agora, como sugeriram Vladimir Voloshinov (1997) e Dominique Maingueneau (2006), a obra parece só fazer sentido na medida em que reflete e refrata a vida que a tornou possível. São escritas que modificam o estatuto tanto da literatura quanto do próprio cotidiano enquanto textualidade.

Talvez seja por isso que Beatriz Resende (2008) afirmou que o viés político tende a atravessar todas as atividades na América Latina de 
hoje. É o fim de uma época em que a literatura definia a si mesma como campo autônomo e unificado. É o esgotamento da autonomia do literário e da autorreferencialidade.

Por isso, a literatura nunca esteve tão viva, e tão em boas mãos: a dos muitos. Os muitos se vingam disseminando, borrando, reescrevendo, tornando cada vez mais públicos os procedimentos do literário, na propaganda, na televisão e na música popular de massa, no cinema, nos livros de autoajuda, nos quadrinhos, nos muitos tons, às vezes tão poucos, dos mais vendidos.

Em outras palavras: a perda da autonomia e da literariedade do literário é um signo de sua potência, agora enquanto força centrífuga da multidão. A perda da autonomia é parte de processos de singularização, de autonomias provisórias outras e estratégias pontuais e específicas, étnicas, de classe, de região, de geração, de gênero..., que delimitam e constrangem a escrita da escritura desde dentro. Nas palavras de Susana Scramin, "é aquela que assume o risco inclusive de deixar de ser literatura, ou ainda, de fazer com que a literatura se coloque num lugar outro, num lugar de passagem entre os discursos" (2007, p. 12).

A potência da literatura de multidão encarna, como utopia assumidamente utópica, um devir-Brasil do mundo e um devir-mundo do Brasil, MundoBraz, nas belas palavras de Giuseppe Cocco:

MundoBraz corresponde à "descoberta da miséria mais total que explode em direção à luz, ao Messias". MundoBraz, na medida em que a cosmologia da libertação encontra a materialíssima "nova imanência" da cosmologia ameríndia, com sua "internalização" de uma natureza que "não pode ser o nome do que está fora, pois não há fora, nem dentro", e abre-se ao terreno da criação, da significação do mundo (Cocco, 2009, p. 20).

A literatura de multidão, e sua pós-autonomia, "abre-se ao terreno da criação, da significação do mundo", para além da literatura, sem deixar de tê-la, sempre, como horizonte próximo e instigante.

Giuseppe Cocco (2009, p. 37) problematiza o discurso recorrente de que o Brasil metaforiza a "ontologia" negativa da globalização, que suprime toda "forma-mundo do mundo" e submete as formas de vida ao risco constante de precarização e de fragmentação, de perda da capacidade de acolhimento e abertura.

O Brasil encarna, também, sua contraparte e engendra o contradiscurso exemplar pós-capitalista ao barrocizar as "mil folhas que 
constituem os múltiplos planos da globalização" (Cocco, 2009, p. 42). Ruptura com a tradição colonial e pós-colonial e recusa à imagem linear de futuro das sociedades ocidentais, presumida pelo capital e pelo progresso. Narrativas de "um tempo novo qualificado", temporalidade intensiva e espacialidade horizontalizante. Imanência e estratos; consistência e organização. Processos de homo e heterogeneização (Cocco, 2009, p. 54). Um espaço de intensificação de trocas e de práticas de resistência e produção, material e imaterial, dos pobres contra as formas de subordinação e rebaixamento. Potência de diferenciação e resistência.

É sob o signo de uma multiplicidade ambivalente, antropofágica, autofágica, que estamos vivendo, capaz de tanto recusar os modos dominantes de produção de escritas associados à literatura quanto incorporar a todos. É a intensidade da vida na metrópole hostil que se entranha nos universos privados, se imiscui na beleza achatada da propaganda luminescente do monitor de vídeo, até o espaço sem privacidade da vida doméstica, no trabalho e do lazer.

Toda visada apriorística sobre a literatura brasileira contemporânea, em particular ao que estou chamando de literatura de multidão, é um encontro tácito com o equívoco. É preciso cada vez mais deixar as obras falarem, naquilo que elas têm de não dito não emoldurável, e de tagarelice invisibilizada pela crítica e por seus métodos.

O crítico não deve esquecer as ferramentas e máquinas de produção de sentido que trouxe da longa tradição da literatura, mas só deve usálas a posteriori, aceitando o risco de nenhuma servir e ter de "comprar" outras, pois a multidão cada vez menos "reproduz" o mundo. "Fabricam-no" para operar aquela "reversão potente da significação geral do sistema de escravidão" (Cocco, 2009, p. 51). A literatura de multidão sempre tem como horizonte próximo, também, as formas de escravidão, e elas são muitas.

A multiplicidade ambivalente é da própria crítica, do próprio pensamento sobre a literatura, também constrangido, muitas vezes contra a própria vontade, a negociar com outras tantas mediações, outras histórias e outras demandas, intelectuais e políticas, cada vez mais próximas e inseridas desde dentro.

Toda obra tem de agora, como nunca antes, estar inserida na vida das culturas e na cultura das vidas.

\section{Oralizar o Brasil pela literatura}


Compreendo a oralização da literatura como um fenômeno singular no ambiente maior daquilo que Josefina Ludmer chamou de "literaturas pós-autônomas" e que me ajuda a pensar as multidões contemporâneas como necessariamente oralizantes, cujos grandes exemplos são as narrativas brasileiras contemporâneas ambientadas em lugares densamente povoados, propiciando uma quantidade infinita de encontros nos quais o diálogo e uma certa positividade do lugar-comum são a moeda de troca.

Oralizar é a moeda comum de resistência aos lugares especiais e de privilégio tão recorrentes nas tradições literárias nacionais, com seus cânones de autores "machos, adultos e brancos". Por isso, meu conceito de oralização é ambivalente, porque pressupõe necessariamente um ambiente de escrita, a partir de onde, e só a partir de onde, é possível resistir pela literatura para além do literário. Oralizar se torna assim a operação semiótica definidora da multidão, sendo sob esse aspecto diferente em tudo do conceito mais antigo de oralidade.

Foi em Edouard Glissant que li a instigante sugestão de que comunidades culturais não hegemônicas "trabalham" para oralizar a literatura:

Penso que hoje trabalhamos no sentido de uma "oralização" da literatura - por um lado porque há poesias orais coletivas que se desenvolvem; por outro lado porque está havendo "oralização" das técnicas da escrita (Glissant, 2005, p. 126).

A oralização tem dupla face ou dois caminhos que se bifurcam, uma por ser coletiva e ter um pé nas memórias comunitárias, outra por ter com a escrita uma relação de hibridização e ruptura. Ela tem um aspecto imaginário, cultural, semiótico em toda amplitude; e um aspecto, diria, maquínico, tecnológico.

É a consciência maquínica das economias do signo que diferencia a oralização da oralidade, cuja relação com a ideologia do estado-nação devemos ter sempre em mente. Os pressupostos da oralidade estão na raiz de toda ideologia nacionalista na medida em que dela descende o próprio conceito de povo e de popular, por extensão, de nação.

A oralização é não nacionalista, é uma espécie não épica de epos, multilíngue e compósito, um epos que não crê no épico nem em sua epopeia. Ela é epos em dois outros sentidos: na premissa da partilha e do comum, aquilo que, como sugeriu Jacques Rancière (2009), nos une e 
nos divide; e numa preocupação com os mortos e com suas memórias, constituídas, tradicionais, e por inventar, abertas, não absolutas, não solipsistas.

Por isso é que pensar em oralização não é pensar em oralidade. A oralidade é um sistema estático; a oralização é errática, não sistemática por estar inserida nos devires não previsíveis das culturas.

Se a oralização não pode esquecer nunca os estudos da oralidade, com ela não deve se confundir. A oralidade já tem uma longa tradição de pesquisa, é um conceito que constitui sistema, porque já possui, tanto na linguística quanto na antropologia e nos estudos literários, por exemplo, importantes bases de pesquisa para se pensar a voz e seus devires, mas é diferente da oralização porque esse sistema está eivado de pressupostos que o conceito de oralização recusa, a saber:

1) uma prática de memória associada a tradições supostamente uniformes e monodiscursivas, "populares", muito arraigadas lá atrás, num passado absoluto;

2) a fala como princípio definidor, em cuja anterioridade temos bons motivos para desacreditar, a oralização é mais sonora que linguageira, é escritura de rastros, para lembrar a crítica de Jacques Derrida ao fonologismo; e

3) uma maneira de delimitar o objeto de pesquisa a partir de unidades estáveis, campos autônomos e exclusividade sociossemiótica.

A oralização tem um pé fora da oralidade porque se situa sempre em contextos de escritas, muitas escritas e escritas de muitos. Ela possui uma relação indissociável com o letramento e com as muitas formas institucionais de uso da escrita, cada dia mais associada às máquinas de produção simbólica multimodais e intergenéricas. Ainda mais porque se sabe que os modos de tratar a alteridade no Ocidente têm sido uma constante passagem pela tradução da oralidade à escrita (Cf. De Certeau, 1995), ser outro sempre foi passar pela escrita de si. Ou, nas palavras de Jacques Derrida, “a todas as línguas praticadas pelos povos que, no entanto, continuam se chamando "povos sem escrita'" (1973, p. 176). A oralização, como a estou pensando aqui, está mais próxima da escrita que da oralidade. Sua relação com a oralidade é lateral, com a escrita é umbilical. 
Pensando nas comunidades africanas de longa tradição de oralização da literatura, Jean Derive nos dá boas pistas para pensá-la como espaço político estratégico para as comunidades não hegemônicas preservarem sua memória e dos seus, expandirem suas formas de produção simbólica para alhures, num processo que pressupõe uma reflexão constante sobre o próprio escrever:

Enquanto autênticos representantes de uma civilização de oralidade é que os escritores africanos produziram a literatura mais concordante com a suas normas escritas e que, ao contrário, é na mesma medida em que eles se integraram a uma civilização da escrita que eles tiveram os meios de operar a oralização dessa literatura. Pois, se admitimos a hipótese aqui defendida, trata-se exatamente de uma oralização da literatura, isto é, da operalização de um processo que supõe um trabalho. Mais do que índices naturalmente dispostos no texto, quase sem o conhecimento dos criadores, as marcas de oralidade são signos, a serviço de estratégias - conscientes ou inconscientes - que devem ser pensadas como efeitos de texto. Não há traços de oralidade, mas efeitos de oralidade (Derive, 2010, p. 24).

Numa perspectiva que leva em conta as máquinas de produção de linguagem contemporâneas, Félix Guattari ajuda a pensar a oralização para além da oralidade a partir de num novo conceito de subjetividade nas sociedades contemporâneas associada a componentes sociais, "industriais" e semióticos a-significantes, formando "máquinas informacionais de signos, funcionando paralelamente ou independentemente, pelo fato de produzirem e veicularem significações e denotações que escapam então às axiomáticas propriamente linguísticas" (Guattari, 1992, p. 14). Para ele, subjetividade é "o conjunto das condições que torna possível que instâncias individuais e/ou coletivas estejam em posição de emergir como território existencial autorreferencial, em adjacência ou em relação de delimitação com uma alteridade ela mesma subjetiva" (Guattari, 1992, p. 19).

Portanto, subjetividade não remete a sujeito ou individualidade, mas é no mais das vezes coletiva. Se a fala plena da metafísica da presença esvazia "as dimensões existenciais da expressão", exprimir tais dimensões exige uma máquina assignificante, que desterritorialize a essencialidade do nome e do sujeito identitário que funda a oralidade enquanto presença a si. 
É no cruzamento de universos maquínicos heterogêneos, de dimensões diferentes, de textura ontológica estranha, com inovações radicais, sinais de maquinismos ancestrais outrora esquecidos e depois reativados, que se singulariza o movimento da história (Guattari, 1992, p. 53).

Sob esse aspecto, a oralização é antes um exercício e um processo em devir, em via de encontrar uma forma, como sugeriu Paul Zumthor pensando na poesia sonora, sem nunca efetivamente se "conformar". Tendo como dois inimigos úteis a palavra e a música, a poesia sonora reage contra o fechamento operado pela linguagem, pratica uma comunicação fora da linguagem, pois se alimenta de processos de significação de diversas ordens: materiais e energéticos, de humor e afeto, representações mentais individuais e coletivas, "máquinas" desejantes e "máquinas" abstratas. Suas duas recusas históricas, da música e da palavra, objetivam a contribuição de "fluxos indiferenciados" (Zumthor, 1998).

Diante dela, o leitor da escrita literária tradicional perde a segurança de seu espaço corporal unificante, ele não sabe onde pôr os olhos. As nossas faculdades de delimitação ordenadora do espaço se perdem, não importa tanto encontrar o significado das palavras... A oralização questiona a tirania dos signos que se impõem como única realidade.

$\mathrm{Na}$ oralidade maquínica, uma das muitas formas de oralização, nenhum conteúdo da subjetividade está imune à influência de diversos sistemas, que não são sinônimos da chamada sociedade das máquinas ou do virtual, pois as máquinas sempre estiveram, e em toda parte.

A voz de qualquer suposto poeta de primeira primeiridade só é possível em um ambiente maquínico: são máquinas tudo o que dá pertinência, existência e potência. Um objeto não é nada fora do conjunto a que pertence, de seu "agenciamento maquínico de enunciação".

A oralização, portanto, não articula (só ou principalmente) questões de identidade. Sua inserção num passado, numa tradição, numa comunidade, não para aí, no "identitário". Como estratégia de leitura, o tempo é sempre o presente, "carregado de agoras". De resíduos, contemporâneos não contemporâneos, potenciais formas por vir.

Ela não porta nenhuma saudade, todos os seus mortos estão vivos, no presente da obra. Não é o passado ou a memória de uma outra semiose em uma obra do presente do leitor, é uma espécie de futuro do 
texto atual, na medida em que não remete a um antes fundado lá atrás, só pode ser encontrada a posteriori, como "efeito".

Se o romance é um gênero que reflete a forma de percepção intergenérica da modernidade, como queria Mikhail Bakhtin, associado à leitura silenciosa do livro, a oralização é intermidial. Ela não é encontrável só nas formas da interação vocal. Ela é tanto o devir da literatura para outras linguagens quanto a permanência, em nova base, da literatura como gênero do discurso moderno nas outras mídias e artes.

A oralização está associada a um novo élan cultural pós-romanesco que vai da literatura para tantas mídias e destas para o texto literário, sobretudo narrativo. Essa dominante cultural não é oral; é também oral, mas é principalmente sonora, para mim mais definidora do contemporâneo do que o imagético e/ou visual tão comuns no discurso pós-moderno. Se um dos pressupostos da teoria contemporânea é o de que vivemos num mundo de imagens, pouco se tem dito que a "imagem contemporânea", seja lá o que isso for, aparece no mais das vezes acompanhada da voz e do som, ou seja, a imagem contemporânea é fortemente acústica.

Em algumas narrativas contemporâneas o grafite, a música popular em geral e o rap em particular, a televisão e a conversa cotidiana são mais determinantes que as tradições do livro e da leitura. A esfera acústica faz a escrita, a Literatura (com "L" maiúsculo), ser habitada por uma outra semiosfera, por um cruzamento diagonal do sonoro no livro.

Oralizar redimensiona o habitus linguageiro, institucional e excludente, e coloca a nossa disposição outras formas de formar, outras estruturas, outro tipo de signo e de interação sociodiscursiva, outros lugares de dizer e do fazer, sempre pela língua e pela escrita, nunca sem elas, mas não confinado a elas.

A oralização da literatura aprofunda o caráter vivencial do discurso. Ao quebrar o corte epistemológico entre dizer e estar no mundo, a vivência põe ênfase na "dimensão comunitária da vida social", "duração feita de pequenos 'instantes eternos', que, de modo fractal, formam o mosaico de uma socialidade que não possui um sentido unívoco", antes é feita de "significações ao mesmo tempo efêmeras dentro do momento, mas não menos perduráveis em sua globalidade" (Maffesoli, 2001, p. 177). 
Trata-se de uma pulsão que atravessa a escrita e a oralidade numa relação de diálogo, fusão, tensão, pastiche, incorporação, comentário, citação, relação não "interlingual", inter e intrassistêmica, pressupondo a literatura e suas escritas sempre num contexto de multiplicidades. Nem fora nem dentro, todas as linguagens, todas as mídias e todas as artes se atravessam com a cultura comum das práticas cotidianas.

A oralização tem a toda vez um prefixo "inter" e só se interessa por escritas, no sentido derrideano de rastros, materialidades de grama. Ela se alimenta de "um método interpretativo centrado sobre os resíduos, sobre os dados marginais", como quer o paradigma indiciário de Carlo Guinsburg (1989), “a viva voz, pelos gestos, pelos olhares”, todos nascidos da "concretude da experiência", dando especial importância a elementos "inicialmente considerados não pertinentes ao texto os elementos ligados à oralidade e à gestualidade, depois os elementos ligados ao caráter físico da escrita" (Guinsburg, 1989, p. 157).

Com a urgência do cotidiano contra a opressão e o empobrecimento, a oralização pressiona o discurso constituinte da literatura como campo literário autônomo a tornar-se multiacentual e polivocal.

Em outras palavras, oralizar a literatura é dar conta dos resíduos das resistências dos muitos, de seus diversos modos de produção de linguagem e de vida através de um atravessar da escrita pelo sonoro, aquilo que define a nossa época e que é por hipótese o "sistema modelizante primário" das maiorias minoritárias.

\section{Referências}

CEVASCO, Maria Elisa (2003). Dez lições sobre estudos culturais. São Paulo: Boitempo.

COCCO, Giuseppe (2009). MundoBraz: o devir-mundo do Brasil e o devir-Brasil do mundo. Rio de Janeiro: Record.

DE CERTEAU, Michel (1995). Etnografia: a oralidade e o espaço do outro. In: DE CERTEAU, Michel. A escrita da história. São Paulo: Forense.

DENNING, Michael (2005). O fim da cultura de massa. In: DENNING, Michael. A cultura na era dos três mundos. São Paulo: Francis.

DERRIDA, Jacques (1973). Gramatologia. São Paulo: Perspectiva. 
DERIVE, Jean (2010). Literarização da oralidade, oralização da literatura nas culturas africanas. In: DERIVE, Jean. Oralidade, literarização e oralização da literatura. Belo Horizonte: Editora da UFMG. (Cadernos Viva Voz.)

GIROUX, Henry A. (2003). Atos impuros: a prática política dos estudos culturais. Porto Alegre: Artmed.

GLISSANT, Edouard (2005). O caos-mundo: por uma estética da relação. In: GLISSANT, Edouard. Introdução a uma poética da diversidade. Tradução de Enilce Albergaria Rocha. Juiz de Fora: EDUFJF.

GUATTARI, Félix (1992). Caosmose: um novo paradigma estético. São Paulo: Editora 34.

GUINSBURG, Carlo (1989). Sinais: raízes de um paradigma indiciário. In: GUINSBURG, Carlo Letras.

JOHNSON, Richard (2000). O que é, afinal, estudos culturais. In: SILVA, Tomaz Tadeu da (Org.). O que é, afinal, estudos culturais. Belo Horizonte: Autêntica.

LAMAIRE, Ria (1994). Repensando a história literária. In: LAMAIRE, Ria. Tendências e impasses. Rio de Janeiro: Rocco.

LUDMER, Josefina (2007). Literaturas pós-autônomas. Revista de Crítica Literaria y de Cultura, n. 17. Disponível em: <http://culturaebarbarie.org/sopro/n20.pdf>.

MAFFESOLI, Michel (2001). A vivência. In: MAFFESOLI, Michel. Elogio da razão sensível. Petrópolis: Vozes.

MAINGUENEAU, Dominique (2006). Um posicionamento na interlíngua. In: MAINGUENEAU, Dominique. Discurso literário. São Paulo: Contexto.

MATTELART, Armand; NEVEU, Érik (2004). Introdução aos estudos culturais. São Paulo: Parábola.

NEGRI, Antonio (2010). Para uma definição ontológica da multidão. In: DIAS, Bruno Peixe; NEVES, José (Org.). A política dos muitos: povo, classes e multidão. Lisboa: Tinta da China.

CASANOVA, Pascale (2002). A república mundial das letras. São Paulo: Ateliê Editorial.

PIZARRO, Ana (1993). Palabra, literatura y cultura en las formaciones discursivas coloniales. In: PIZARRO, Ana. (Org.). América Latina: palavra, literatura e cultura. Campinas: UNICAMP.

RANCIÈRE, Jacques (2009). A partilha do sensível: estética e política. São Paulo: 34. 
RESENDE, Beatriz (2008). A literatura brasileira na era da multiplicidade. In: RESENDE, Beatriz. Contemporâneos: expressões da literatura brasileira no século XXI. Rio de Janeiro: Casa da Palavra; Biblioteca Nacional.

SCRAMIN, Susana (2007). Literatura do presente: história e anacronismo dos textos. Chapecó: Argos.

VOLOSHINOV (1997). Marxismo e filosofia da linguagem. 7. ed. São Paulo: Hucitec.

WILLIAMS, Raymond (2011). Cultura e sociedade: de Coleridge a Orwell. Petrópolis: Vozes.

WILLIS, Susan (1997). Cotidiano: para começo de conversa. Rio de Janeiro: Graal, 1997.

ZUMTHOR, Paul (1998). La poésie et le corps. In: ZUMTHOR, Paul. Écriture e nomadisme. Montreal: L'Hexagone.

Recebido em maio de 2014.

Aprovado em julho de 2014.

\section{resumo/abstract}

\section{A potência oralizante da multidão: por que os estudos culturais ajudam a compreender a experiência dos muitos na literatura contemporânea}

Luciano Barbosa Justino

Meu objetivo neste artigo é fazer um triplo movimento, tendo sempre como horizonte de partida e de chegada o conceito de multidão: $i$ ) compreender como as questões abertas pelos estudos culturais transformam os espaços de legitimação da literatura na medida em que são sintomas de transformações sociais importantes no pós-guerra e no próprio conceito de cultura; ii) demonstrar que a autonomia da literatura baseada em valores estéticoidentitários não consegue dar conta dos muitos devires do contemporâneo; e iii) considerar a literatura brasileira contemporânea como um espaço aberto para uma multiplicidade de formas de vida que têm na oralização da literatura seu processo de semiotização mais significativo.

Palavras-chave: multidão, estudos culturais, autonomia da literatura, multiplicidade. 
The oral power of the crowd: why cultural studies help us understand the experience of the many in contemporary literature

\section{Luciano Barbosa Justino}

My aim in this article is to make a triple movement: $i$ ) show how the questions made by cultural studies transform the spaces of legitimation of the literature in so far as are symptoms of important changes in the cultural sphere and in the own concept of culture; ii) demonstrate that the autonomy based exclusively in esthetic values of the literature is not possible in the contemporary context; and iii) understand the contemporary literature as an open space for a multiplicity of ways of life that find in oral literature their most significant process of semiotization.

Keywords: multitude, cultural studies, autonomy of the literature, multiplicity. 